\title{
RESPONSIVIDADE DE PLANTAS DE MILHO À INOCULAÇÃO COM FUNGOS MICORRÍZICOS ARBUSCULARES DA RIZOSFERA DE IPÊ AMARELO
}

\author{
Jennie Kéllyn da Silva Santos; Marcos Diones Ferreira Santana²; Túlio Silva Lara³ . \\ 1Universidade Federal do Oeste do Pará, Santarém, Pará, Brasil, jenniekellyn@gmail.com \\ 2Universidade Federal do Oeste do Pará, Santarém, Pará, Brasil, santana.mdf@gmail.com \\ 3Universidade Federal do Oeste do Pará. Santarém, Pará, Brasil, tulio.lara@yahoo.com.br
}

\begin{abstract}
RESUMO: Aumentar a produtividade do milho de uma forma sustentável é o desafio de todos os agricultores, objetivou-se isolar e selecionar fungos micorrizicos arbusculares (FMAs) nativos da rizosfera de ipê amarelo (Tabebuia serratifolia (Vahl) Nichols) e avaliar o efeito de sua inoculação em plantas de milho. A extração dos FMAs da rizosfera de ipê amarelo, o isolamento e a inoculação dos esporos em plantas de milho foram realizados no Laboratório de Fisiologia Vegetal e Crescimento de Plantas da Universidade Federal do Oeste do Pará (UFOPA) em outubro de 2017. O efeito da simbiose no crescimento inicial das plantas foi avaliado em condições de laboratório, sob iluminação artificial com fotoperíodo de 12 horas e regas diárias por 15 dias. Foram isolados 410 esporos de FMAs pertencentes a três espécies: Glomus clarum, G etunicatum e G. geosporum. Os FMAs colonizaram de forma eficiente o sistema radicular das plantas de milho e proporcionaram, na primeira coleta, incrementos superiores a 100\% na massa seca da raiz e da parte aérea, quando comparadas às plantas controle. Conclui-se que a inoculação com os FMAs, nativos da rizosfera do ipê amarelo, aumenta a massa seca das plantas, tornando-se, um inoculante promissor para o cultivo do milho.
\end{abstract}

PALAVRA CHAVE: Crescimento vegetativo, Micorrizas, Produtividade.

\section{RESPONSIVENESS OF CORN PLANTS TO INOCULATION WITH ARBUSCULAR MYCORRHIZAL FUNGI OF THE RHIZOSPHERE OF IPÊ AMARELO}

ABSTRACT: Increasing corn productivity in a sustainable manner is the challenge of all farmers, and thus the objective was to isolate and select arbuscular mycorrhizal fungi (AMF) native to the rhizosphere of ipê amarelo (Tabebuia serratifolia (Vahl) Nichols) and to evaluate the effect of their inoculation in corn plants. The AMF extraction from the rhizosphere of ipê amarelo, the isolation and inoculation of the spores in corn 
plants were carried out in the Laboratory of Vegetal Fisiology and Growth of Plants of the Universidade Federal do Oeste do Pará (UFOPA) in Octuber 2017. The effect of symbiosis on initial plant growth was evaluated under laboratory conditions, under artificial lighting with photoperiod of 12 hours and daily watering for 15 days. 410 spores of AMF belonging to three species, Glomus clarum, G etunicatum and $G$. geosporum were isolated. AMF efficiently colonized the root system of corn plants and provided, in the first collection, increments greater than $100 \%$ in root dry mass and aerial parts, when compared to control plants. It is concluded that the inoculation with AMF, native to the rhizosphere of ipê amarelo, increases the dry mass of the plants, becoming a promising inoculant for corn cultivation.

KEYWORD: Mycorrhizae, Productivity, Vegetative growth.

\section{RESPUESTA DE LAS PLANTAS DE MAÍZ A LA INOCULACIÓN CON HONGOS MICORRÍZICOS ARBUSCULARES DE LA RIZOSFERA DE IPÊ AMARILLO}

RESUMEN: El aumento de la productividad del maíz de una forma sostenible es el desafío de todos los agricultores, se ha objetivado aislar y seleccionar hongos micorrizas arbusculares (HMA) nativos de la rizosfera de ipê amarillo (Tabebuia serratifolia (Vahl) Nichols) y evaluar el efecto de su inoculación en las plantas de maíz. La extracción de los HMA de la rizosfera de ipê amarillo, el aislamiento y la inoculación de las esporas en plantas de maíz se realizaron en el Laboratorio de Fisiologia Vegetal e Crescimento de Plantas de la Universidade Federal do Oeste de Pará (UFOPA) en octubre de 2017. El efecto de la simbiosis en el crecimiento inicial de las plantas fue evaluado en condiciones de laboratorio, bajo iluminación artificial con fotoperíodo de 12 horas y riegos diarios por 15 días. Se aislaron 410 esporas de HMA pertenecientes a tres especies: Glomus clarum, G etunicatum y G. geosporum. Los HMA colonizaron de forma eficiente el sistema radicular de las plantas de maíz y proporcionaron, en la primera colecta, incrementos superiores al 100\% en la masa seca de la raíz y de la parte aérea, cuando comparadas a las plantas control. Se concluye que la inoculación con los HMA, nativos de la rizosfera del ipê amarelo, aumenta la masa seca de las plantas, convirtiéndose, en un inoculante prometedor para el cultivo del maíz.

PALABRA CLAVE: Crecimiento vegetativo, Micorrizas, Productividad.

Aumentar a produção de alimentos

para alimentar uma população em crescimento, produzir mais matérias-

primas para um mercado bioenergético 
potencialmente enorme, aliados à mãode-obra rural cada vez mais escassa e com os problemas inerentes às mudanças climáticas, são os maiores desafios para a agricultura do século XXI (FAO, 2009). Sobre tudo diante da responsabilidade de aumentar a produção através de técnicas mais eficientes e sustentáveis (BORGES et al., 2009).

Uma das alternativas é adotar técnicas de produção com o emprego de micro-organismos que auxiliam no crescimento, produtividade, além de possibilitar maior tolerância aos estresses bióticos e abióticos (ALBINO et al., 2006). Nesse sentido, os Fungos Micorrizicos Arbusculares (FMA), por meio da relação mutualista formada entre a raiz da planta hospedeira e o micélio intra-radicular (BRUNDRETT, 2009), representam importante ferramenta na produção agrícola, principalmente em culturas anuais como a soja, feijão e milho, as quais apresentam elevado grau de dependência micorrízica (PARNISKE, 2008).
Os FMAs favorecem o crescimento das plantas, através de uma maior absorção de água e nutriente, especialmente os de baixa mobilidade no solo como o fósforo (ZHAO et al., 2015). Machineski et al. (2009) observaram maior crescimento vegetativo da Aspidosperma polyneuron Müll. Arg. após a inoculação com FMAs. Shinde e Singh (2017) encontraram em plantas de milho-doce, submetidas ao estresse salino, maior acumulo de biomassa e produtividade em plantas inoculadas com FMAs do que em plantas não inoculadas. Aguegue et al. (2017) também observaram aumento no crescimento de plantas de milho micorrizadas.

O milho é cultivado em todas as regiões brasileiras, tanto em grandes extensões territoriais contribuindo para a segurança alimentar mundial, como em pequenas propriedades sendo a base da agricultura familiar. A área plantada na safra 2016/2017, foi de 17.592,1 mil hectares, sendo 10\% superior à área plantada no período 2015/2016 (CONAB, 2017). No entanto, 
a queda na produtividade está diretamente associada ao déficit hídrico e à adubação incorreta, que tem os efeitos amenizados a partir da inoculação de FMA (LIU et al., 2016).

A seleção de FMAs para inoculação em plantas de milho é complexa, pois trata-se de uma espécie cultivada em todo o território brasileiro, e sabe-se que existe um grau de especificidade entre o tipo de solo, o FMA e a planta (HIPPLER et al., 2011). Logo, procurou-se encontrar FMAs que colonizassem diferentes tipos de solos e com associações generalistas. A partir disso, foi selecionado o Ipê amarelo (Tabebuia serratifolia (Vahl) Nichols), que é nativa do Brasil e ocorre em diferentes tipos de solos (LORENZI, 2000). A seleção de FMAs capazes de colonizar diferentes espécies vegetais mesmo em solos empobrecidos, como a região oeste do Pará, possibilitará aumentar a produtividade de forma sustentável atendendo a carência regional e mundial.

Contudo, a comprovação da colonização das raízes do milho por
FMAs selecionados da rizosfera do ipê amarelo é de grande importância, uma vez que são escassos os trabalhos na literatura que tentaram isolar FMAs de plantas nativas, como o ipê amarelo e inoculá-los em plantas cultivadas, como o milho. Nesse sentido e com o intuito de contribuir com ferramentas para auxiliar a produção de milho, objetivouse: i) isolar e selecionar esporos nativos de fungos micorrizicos arbusculares da rizosfera do ipê amarelo; ii) realizar a inoculação em plantas de milho; iii) avaliar o crescimento inicial das plantas de milho, após a inoculação.

Para a coleta do solo rizosférico foram escolhidas ao acaso, quatro plantas adultas de ipê amarelo. Estas estão distribuídas na cidade de Santarém-PA, nas dependências da Universidade Federal do Oeste do Pará (UFOPA), Campus Tapajós (2²5'6.39"S 5444'28.58"W). Em cada planta, foram coletadas quatro amostras de solo, uma em cada quadrante, na projeção da copa, a uma profundidade de $20 \mathrm{~cm}$, para formação de quatro amostras compostas. As amostras foram 
armazenadas individualmente, em sacos plásticos, previamente identificados e encaminhadas para extração e quantificação dos esporos de FMA.

No Laboratório de Fisiologia Vegetal e Crescimento de Plantas da Universidade Federal do Oeste do Pará (UFOPA), a densidade e ocorrência relativa dos esporos dos FMAs do solo rizosférico foram determinadas por contagem direta, por meio de isolamento em placa de Peri $(90 \mathrm{~mm}$ de diâmetro). Para isso, foram retirados 100 g da amostra composta para extração dos esporos a partir do peneiramento em via úmida (GERDEMANN; NICOLSON, 1963) e da centrifugação em sacarose 50\% (JENKINS, 1964). Os esporos foram recolhidos em peneiras de $44 \mathrm{~mm}$, transferidos para placa de Petri (90 mm de diâmetro), mensurados e isolados com auxílio de microscópio estereoscópico. A identificação seguiu análise morfológica clássica como descrito por Morton et al. (1995).
A inoculação das plantas de milho com os FMAs foi realizada em condições de laboratório. Para isso, vasos plásticos com capacidade para $400 \mathrm{~mL}$ foram preenchido com $150 \mathrm{~g}$ de substrato comercial isento de microorganismo, mais $50 \mathrm{~g}$ do inoculante, que é o solo rizosférico do ipê amarelo.

Cada amostra composta foi utilizada como inoculante para 4 vasos, totalizando 16 vasos com inoculante e mais 4 vasos controle, sem inoculante. Nos vasos foram plantadas 5 sementes de milho, que foram previamente desinfestadas superficialmente. As plantas foram cultivadas sob iluminação artificial com fotoperíodo de 12 horas, irrigação diária para manter a capacidade de campo em 70\% e temperatura de $27^{\circ} \mathrm{C}$. Para o controle, as plantas de milho foram cultivadas nas mesmas condições e realizaram-se os mesmos procedimentos, porém sem a inoculação dos FMAs.

A quantificação da massa seca ocorreu aos 7 e 15 dias após a germinação, onde se separou a parte aérea da raiz de duas plantas por vaso, 
totalizando 32 plantas inoculadas e 8 plantas controle, em cada coleta. $\mathrm{O}$ material vegetal foi acondicionado em estufa com circulação forçada de ar, a uma temperatura próxima de $60^{\circ} \mathrm{C}$, até atingir peso constante, para então ser pesado e ter a massa seca mensurada em balança analítica com precisão de $0,01 \mathrm{~g}$.

Para confirmação da colonização micorrízica, $1 \mathrm{~g}$ de raiz fina foi inicialmente lavado em água corrente, em seguida, submetido a clareamento com $\mathrm{KOH} 10 \%$, acidificado com $\mathrm{HCl} 1 \%$ e corado com azul de tripano 0,05\% em lactoglicerol (PHILLIPS; HAYMAN, 1970). Por fim, as raízes foram cortadas em segmentos de $\pm 1 \mathrm{~cm}$ de comprimento e examinadas em microscópio para avaliação da presença de estruturas típicas da infecção por FMA (hifas, vesículas e arbúsculos).

Os dados de densidade de esporos e ocorrência relativa foram submetidos à análise descritiva. Os dados obtidos de massa seca foram submetidos ao teste de normalidade e os gráficos foram confeccionados através do Programa Sigma Plot (versão 12.5, Systat Software (hicago, IL, USA).

Foram isolados 410 esporos de FMAs do solo rizosférico do ipê amarelo. Estes pertencentes a três espécies do gênero Glomus, sendo elas G. clarum, G etunicatum e G. geosporum. A densidade total de esporos isolados, assim com a ocorrência relativa por espécies (Tabela 1).

Regiões perturbadas, como as áreas em que a rizosfera do ipê amarelo foi coletada, frequentemente apresentam uma maior densidade de esporos de FMAs em relação às áreas não antropizadas (VILAÇO et al., 2014). Isso se deve ao aumento do grau de estresse do ambiente e à sua natureza biológica, pois trata-se de uma estrutura de disseminação, resistência e sobrevivência (MIRANDA, 2008; CARNEIRO et al., 2009), o que garante ao FMA alta capacidade de adaptação em locais adversos, características vantajosas na região Oeste do Pará. 
Tabela 1. Densidade (D) e Ocorrência Relativa (OR) de esporos de Fungos Micorrízicos Arbusculares em amostras de solos rizosféricos de quatro plantas de ipê amarelo.

\begin{tabular}{lcc}
\hline Espécie & D & *OR (\%) \\
\hline Glomus clarum & 130 & 31,7 \\
G. etunicatum & 139 & 33,9 \\
G. geosporum & 141 & 34,4 \\
\hline Total & 410 & 100 \\
\hline *Ocorrência relativa: $n^{\circ}$ de esporos que a espécie apresentou em relação ao total de esporos isolados.
\end{tabular}

A predominância do gênero Glomus pode ser justificada inicialmente por sua vasta distribuição e ampla adaptação às variações ambientais (CORRÊA et. al., 2010). Sobre tudo, sua ocorrência tem sido relatada amplamente para áreas impactadas (CARNEIRO et al., 2009), com baixa fertilidade do solo e teores de nitrogênio (BERBARA et al., 2006).

A versatilidade do gênero em colonizar diferentes espécies vegetais, o torna eficiente em colonizar também as raízes do milho (Figura 1), isso comprova o seu potencial de uso na agricultura.

A alta densidade das hifas extracelulares caracteriza importante estrutura na aquisição de fósforo do solo (NOVAIS et al., 2014). Essas estruturas funcionam como extensões do sistema radicular, consequentemente aumentam sua capacidade de explorar maior volume de solo e promovem o crescimento mais acelerado das plantas, assim como pode garantir aumento da produtividade em campo (LUCENA et al., 2013) e benefícios a agricultara familiar.

Quanto à responsividade das plantas de milho foi observado que, as plantas inoculadas com FMAs apresentaram maior crescimento da parte aérea do que as plantas controles, em ambas os períodos de coletas (Figura 2). No entanto, para a massa seca da raiz, apenas foi observado incremento na primeira coleta (Figura 2B). 
Figura 1. Colonização do sistema radicular de milho submetido à inoculação por fungos micorrízicos arbusculares da rizosfera de Ipê amarelo. Setas indicam: A-C) Hifas; D) Vesícula; E) Esporo; F) Arbúsculo.
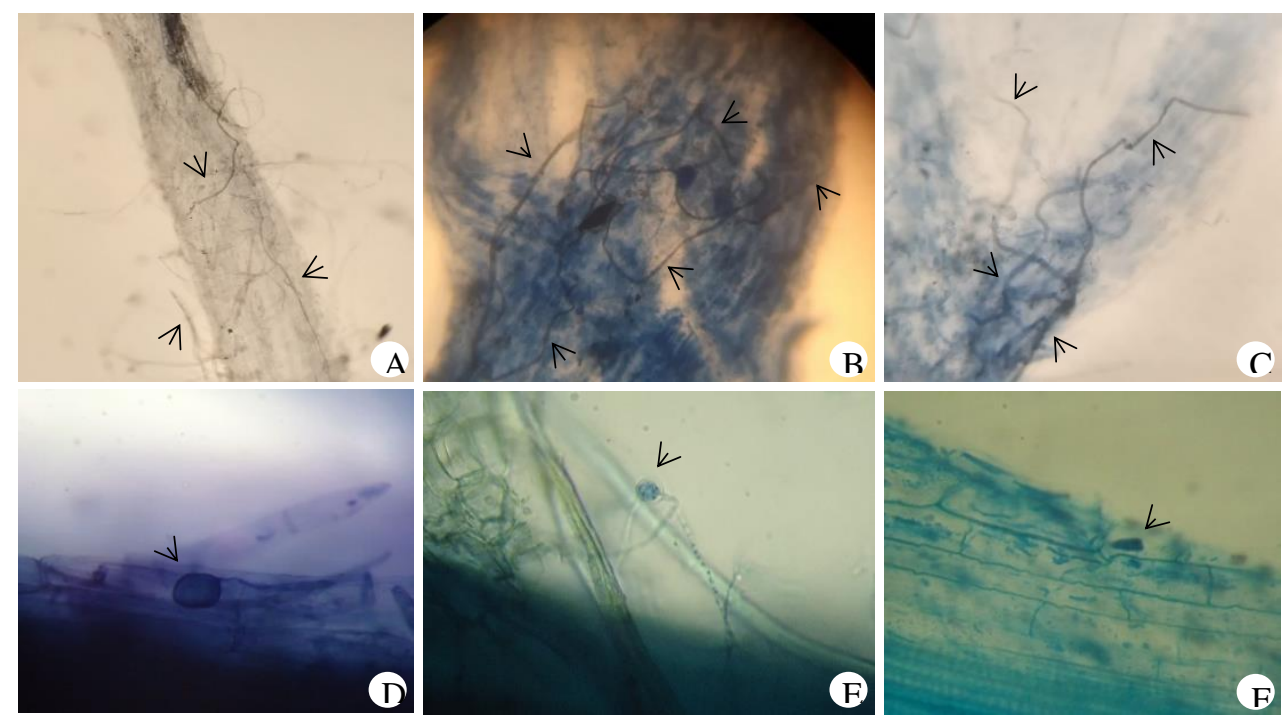

Figura 2. Massa seca da parte aérea em dois períodos diferentes de coleta, aos sete e 15 dias após emergência. As barras representam o erro padrão das médias das plantas micorrizadas $(n=32)$ e das plantas controle $(n=8)$.

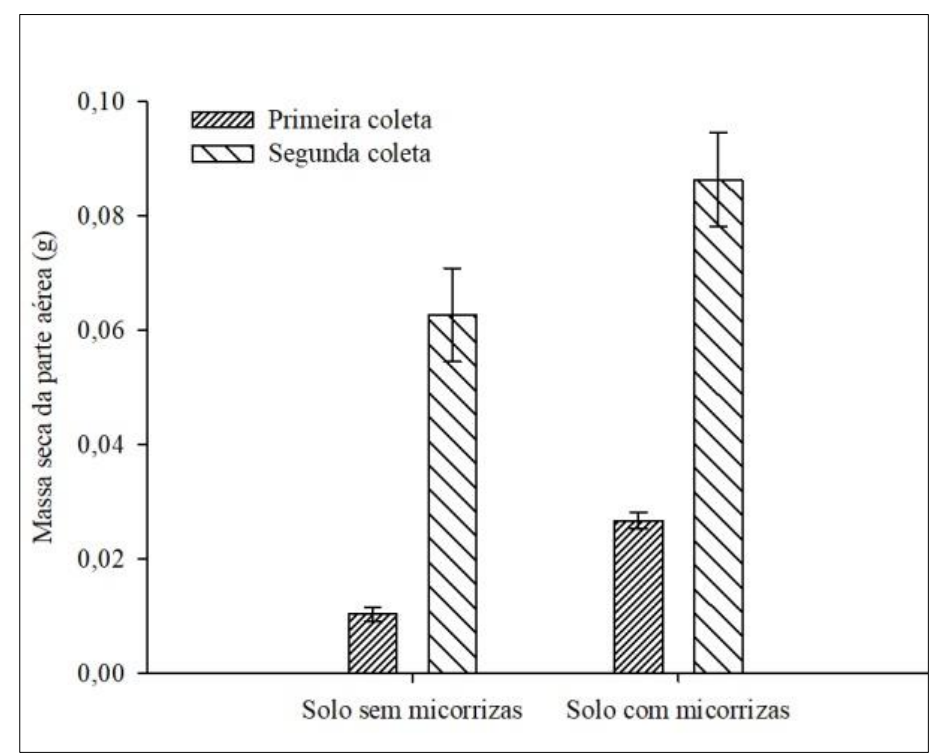


Figura 3. Massa seca da raiz em dois períodos diferentes de coleta, aos 7 e 15 dias após emergência. As barras representam o erro padrão das médias das plantas micorrizadas $(n=32)$ e das plantas controle $(n=8)$.

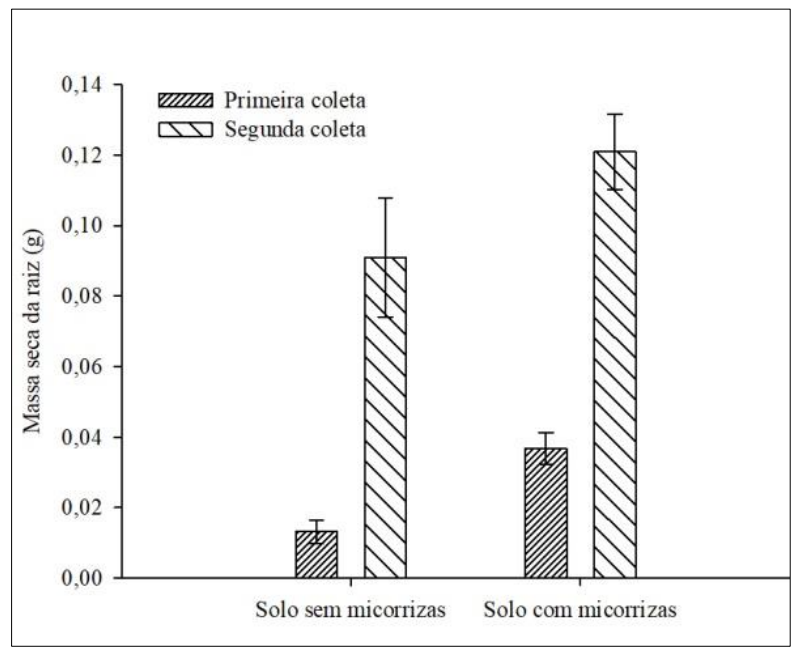

$\mathrm{Na}$ primeira coleta os FMAs de carboidratos e aminoácidos, além proporcionaram incrementos superiores a $100 \%$ na massa seca da raiz e da parte aérea, comparados ao controle. Gerlach et al. (2015) e Aguegue et al. (2017) também observaram efeitos benéficos no crescimento de plantas de milho inoculadas com FMAs. A simbiose das plantas com os FMAs é fundamental para melhorar o estado fisiológico das plantas, pois aumenta os teores de fósfora (P), enxofre (S) e zinco (Zn) nas folhas, proporciona uma elevação global no metabolismo de C versus $\mathrm{N}$, o que reflete positivamente nos teores de induzir a expressão de genes de defesa sistêmica e aumentar a atividade das enzimas do sistema antioxidante (NADEEM et al., 2014; NOVAIS et al., 2014; GERLACH et al., 2015).

No presente trabalho, o efeito benéfico da inoculação com FMAs foi mais perceptível na primeira coleta aos 7 dias após a emergência, possivelmente devido a uma maior absorção de P. As plantas são mais sensíveis ao $P$ na fase inicial de crescimento, uma vez que este nutriente é responsável pela 
transferência de energia da célula, na respiração e na fotossíntese, além de também ser componente estrutural dos ácidos nucléicos, assim como de muitas coenzimas, fosfoproteínas e fosfolipídeos (SHEN et al., 20011; BALEMI; NEGISHO, 2012).

O gênero Glomus (G. clarum, G. etunicatum e G. geosporum) foi dominante na rizosfera do ipê amarelo e sua presença configura ampla adaptação às variações ambientais da região do Oeste do Pará. As três espécies isoladas, colonizaram com sucesso o sistema radicular do milho e atribuíram incremento na massa seca das plantas, tanto na parte aérea como nas raízes, evidenciando a versatilidade do gênero em colonizar diferentes grupos vegetais e conferir vantagens positivas frente às plantas não colonizadas, tornando essa técnica promissora para o cultivo sustentável e eficiente do milho na região.

\section{REFERÊNCIAS}

AGUEGUE, M. R; NOUMAVO, P. A.; DAGBENONBAKIN, G.; AGBODJATO, N. A.; ASSOGBA, S.; KODA, A. D.;
ADJANOHOUN, A.; RIVERA, R.; PONS, B. M. de la N.; BABA-MOUSSA L. Arbuscular mycorrhizal fertilization of corn (Zea mays L.) cultivated on ferrous soil in southern benin. Journal of Agricultural Studies, v.5, p.99 - 115, 2017.

ALBINO, U.; SARIDAKIS, D. P.; FERREIRA, M. C.; HUNGRIA, M.; VINUESA, P.; ANDRADE, G. High diversity of diazotrophic bacteria associated with the carnivorous plant Drosera villosa var. villosa growing in oligotrophic habitats in Brazil. Plant and Soil, v.287, p.199 - 207, 2006.

BALEMI, T; NEGISHO, K. Management of soil phosphorus and plant adaptation mechanisms to phosphorus stress for sustainable crop production: a review. Journal of Soil Science and Plant Nutrition, v.12, p.547 - 562, 2012.

BERBARA, R. L. L.; SOUZA, F. A. de; FONSECA, H. M. A. Fungos micorrízicos arbusculares: muito além da nutrição. Nutrição Mineral de Plantas. (Ed.). Viçosa: SBCS, v.3, p.53 - 88, 2006.

BORGES, L; A. C.; REZENDE, J. L. P.; PEREIRA, A. A. Evolução da legislação ambiental no Brasil. Revista em Agronegócio e Meio Ambiente, v.2, p.447 - 466, 2009.

BRUNDRETT, M. C. Mycorrhizal associations and other means of nutrition of vascular plants: understanding the global diversity of host plants by resolving conflicting information and developing reliable 
means of diagnosis. Plant and Soil, v.320, p.37 - 77, 2009.

CARNEIRO, M. A. C.; SOUZA, E. D.; REIS, E. F.; PEREIRA, H. S.; AZEVEDO, W. R. Atributos físicos, químicos e biológicos de solo de Cerrado sob diferentes sistemas de uso e manejo. Revista Brasileira de Ciência do Solo, v.33, p.147 - 157, 2009.

CONAB. Companhia Nacional de Abastecimento. Acompanhamento da safra brasileira de grãos. v.4, SAFRA 2016/17, n.12 - Décimo segundo levantamento. Brasília: CONAB, 2017.

CORRÊA, H. de S.; KNOECHELMANN, C. M.; MELLO, A. H. de; PEREIRA; F. D.; MICHELOTTI, F.; MANESCHY, R. Q. Fungos micorrízicos arbusculares associados às culturas cultivadas em sistemas agroflorestais e em monoculturas em projetos de assentamento do sudeste paraense. Revista Agroecossistemas, v.2, p.13 - 17, 2010.

FAO. FOOD AND AGRICULTURE ORGANIZATION OF THE UNITED NATIONS. Sales and marketing group, p.180, 2009.

GERDEMANN, J. W.; NICOLSON, T. H. Spores of mycorrhizal Endogone species extracted from soil by wtsieving and decanting. Transactions of Britisch Mycological Society. v.46, p.235 - 244, 1963.

GERLACH, N.; SCHMITZ, J.; POLATAJKO, A.; SCHLÜTER, U.; FAHNENSTICH, H.; WITT, S.; FERNIE; A.
R.; UROIC, K.; SCHOLZ, U.; SONNEWALD, U.; BUCHER, M. An integrated functional approach to dissect systemic responses in maize to arbuscular mycorrhizal symbiosis. Plant, Cell and Environment, v.38, p.1591 - 1612, 2015.

HIPPLER, F. W. R.; MOREIRA, M.; DIAS, N. M. S.; HERMANN, E. R. Fungos micorrízicos arbusculares nativos e doses de fósforo no desenvolvimento do amendoim RUNNER IAC 8861. Revista Ciência Agronômica, v.42, p.605 - 610, 2011.

JENKINS, W. R. A rapid centrifugalfloration technique for separating nematodes from soil. Plant Disease Report, v.48, p.692, 1964.

LIU, S.; GUO, X.; FENG, G.; MAIMAITIAILI, B.; FAN, J.; HE, $X$. Indigenous arbuscular mycorrhizal fungi can alleviate salt stress and promote growth of cotton and maize in saline fields. Plant and Soil, v.398, p.195 - 206, 2016.

LORENZI, H. Árvores brasileiras: manual de identificação e cultivo de plantas arbóreas nativas do Brasil. Nova Odessa: Instituto Plantarum, 2000, v.1, 367 p.

LUCENA, V. B.; RAIMAM, M. P.; CARDOSO, N. A.; ALBINO, U. B. Influência de fungos micorrízicosarbusculares em paricá (Schizolobium amazonicum) cultivado no estado do Pará. Pesquisa Florestal Brasileira, v.33, p.235 - 241, 2013. 
MACHINESKI, O.; BALOTA, E. L.; FILHO, A. C.; ANDRADE, D. S.; SOUZA, J. R. P. DE. Growth responses of peroba rosa seedlings due to arbuscular mycorrhizal fungi inoculation. Ciência Rural, v.39, p.567 - 570, 2009.

MIRANDA, J. C. C. Cerrado: Micorriza arbuscular, ocorrência e manejo. Planaltina, Embrapa Cerrados, 2008, $169 \mathrm{p}$.

MORTON, J. B, BENTINVENGA, S. P.; BEVER, J. D. Discovery, measurement, and interpretation of diversity in symbiotic endomycorrhizal fungi (Glomales, Zygomycetes). Canadian Journal of Botany, v.73, p.25 - 32, 1995.

NADEEM, S. M.; AHMAD, M.; ZAHIR, Z. A.; JAVAID, A.; ASHRAF, M. The role of mycorrhizae and plant growth promoting rhizobacteria (PGPR) in improving crop productivity under stressful environments. Biotechnology Advances, v.32, p.429 - 448, 2014.

NOVAIS, C. B. de; BORGES, W. L.; JESUS, E. da C.; JÚNIOR, O. J. S.; SIQUEIRA, J. O. Inter- and intraspecific functional variability of tropical arbuscular mycorrhizal fungi isolates colonizing corn plants. Applied Soil Ecology, v.76, p.78 - 86, 2014.

PARNISKE, M. Arbuscular mycorrhiza: the mother of plant root endosymbioses. Nature, v.6, p.763 775, 2008.

PHILLIPS, J. M.; HAYMANN, D. S. Improved procedures for clearing roots and staining parasitic and vesicular- arbuscular mycorrhizal fungi for rapid assessment of infection. Transactions British Mycology Society, v.55, p.158 161, 1970.

SHEN, J.; YUAN L.; ZHANG, J.; LI, H.; BAl, Z.; CHEN, X.; ZHANG, W.; ZHANG F. Phosphorus dynamics: from soil to plant. Plant Physiology, v.156, p.997 - 1005, 2011.

SHINDE, B. P.; SINGH, N. Effect of arbuscular mycorrhizal fungi on growth parameters of sweet corn under $\mathrm{NaCl}$ salinity. International Journal of Current Microbiology and Applied Sciences, v.6, p.1317 - 1325, 2017.

VILAÇO, F. das C. B.; BENTO, R. A.; JÚNIOR, O. J. S. Levantamento dos Fungos Micorrízicos Arbusculares em áreas degradadas terra firme do Município de Lábrea, Amazônia, Brasil. Revista de Educação, Ciência e Tecnologia do IFAM, v.4, p.35 - 43, 2014.

ZHAO, R.; GUO, W.; BI, N.; GUO, J.; WANG, L. ZHAO, J.; ZHANG, J. Arbuscular mycorrhizal fungi affect the growth, nutrient uptake and water status of maize (Zea mays L.) grown in two types of coal mine spoils under drought stress. Applied Soil Ecology, v.88, p.41 - 49, 2015. 